\title{
Assessment and mapping of slope stability based on slope units: A case study in Yan'an, China
}

\author{
Jiandi Zhuang ${ }^{1,2,3}$, Jianbing Peng ${ }^{1, *}$, Yonglong Xu ${ }^{1}$, Qiang Xu ${ }^{3}$, Xinghua Zhu ${ }^{1}$ and Wei Li $^{1}$ \\ ${ }^{1}$ College of Geological Engineering and Surveying of Changan University/Key Laboratory of \\ Western Mineral Resources and Geological Engineering, Xi'an 710054, China. \\ ${ }^{2}$ Department of Civil and Environmental Engineering, The Hong Kong Polytechnic University, \\ Kowloon, Hong Kong, China. \\ ${ }^{3}$ State Key Laboratory of Geohazard Prevention and Geoenvrionment Protection/Collaborative \\ Innovation Center of Geological Prevention, Chengdu 610041, China. \\ *Corresponding author.e-mail: rockfans09@163.com
}

Precipitation frequently triggers shallow landslides in the Loess Plateau of Shaanxi, China, resulting in loss of life, damage to gas and oil routes, and destruction of transport infrastructure and farmland. To assess the possibility of shallow landslides at different precipitation levels, a method to draw slope units and steepest slope profiles based on ARCtools and a new method for calculating slope stability are proposed. The methods were implemented in a case study conducted in Yan'an, north-west China. High resolution DEM (Digital Elevation Model) images, soil parameters from in-situ laboratory measurements and maximum depths of precipitation infiltration were used as input parameters in the method. Next, DEM and reverse DEM were employed to map 2146 slope units in the study area, based on which the steepest profiles of the slope units were constructed. Combining analysis of the water content of loess, strength of the sliding surface, its response to precipitation and the infinite slope stability equation, a new equation to calculate infinite slope stability is proposed to assess shallow landslide stability. The slope unit stability was calculated using the equation at 10-, 20-, 50- and 100-year return periods of antecedent effective precipitation. The number of slope units experiencing failure increased in response to increasing effective antecedent rainfall. These results were validated based on the occurrence of landslides in recent decades. Finally, the applicability and limitations of the model are discussed.

\section{Introduction}

Shallow landslides tend to be widely distributed in landslide-prone areas. They typically involve a small volume of debris flowing at high velocity and with high impact energy, and represent one of the most destructive geo-hazards in many parts of the world which result in damaging roads and buildings, loss of life and bringing environmental problems (Baeza and Corominas 2001; Gomez and Kavzoglu
2005; Zhuang et al. 2014; Wang et al. 2015). Loess is characterised by the presence of macropores, vertical joints, loose texture and sensitivity to water, which makes it prone to erosion and forming landslides (Dijkstra et al. 1995; Derbyshire et al. 2000; Xu et al. 2007; Zhang et al. 2009; Zhang and Liu 2010; Zhu 2012). One-third of the landslides occurring annually in China occur in Loess Plateaus, resulting in loss of life, damage to gas and oil pipelines, destruction of transport

Keywords. Shallow landslide; infinite slope stability equation; return period precipitation; assessment; slope unit. 
infrastructure and reduction in the area of arable land (Li et al. 2007, 2013a; Xu et al. 2009; Wang et al. 2014).

In China, loess covers a total area of approximately $631,000 \mathrm{~km}^{2}$, or $4.4 \%$ of the total land area (Liu 1985). Most of the loess deposits are concentrated in the Loess Plateau, which has an area of approximately $430,000 \mathrm{~km}^{2}$. Although the Loess Plateau is situated in a semi-arid region with about $500 \mathrm{~mm}$ of precipitation per year, most of the rainfall is during the monsoon season from June to September. Frequent storms during this season trigger many shallow landslides every year. These landslides occasionally mobilize into potentially destructive debris flows, resulting in catastrophic damage (Peng et al. 2015). For example, in July 2013, a prolonged heavy rainfall occurred in Yan'an region (on the Loess Plateau) in northwest China with the rainfall exceeding 100-year averages, in terms of both total cumulative precipitation and maximum rainfall intensity, resulted in over a thousand shallow loess landslides. These landslides resulted in 27 deaths and significant damage to road infrastructure (Wang et al. 2015). A similar event occurred in September 2011 in Xi'an and triggered many shallow loess landslides, resulting in 32 deaths and significant damage to buildings and infrastructures (Zhuang and Peng 2014). The Loess Plateau is one of the major oil and gas exploitation areas in China, with a high urban population density and concentration of buildings and roads near slopes. Therefore, for future land-use planning, it is important to develop an effective method to assess the hazards of shallow landslides in this region.

Extensive research has been conducted on rainfall events that trigger landslides, and several early warning predictive models and hazard/ susceptibility models have been proposed and implemented at various areas to predict rainfallinduced landslides and/or identify potentially unstable areas. Examples include empirical rainfall threshold methods (Caine 1980; De Vita et al. 1998; Godt et al. 2006; Guzzetti et al. 2007, 2008; Baum and Godt 2010; Gupte et al. 2013; Zhuang et al. 2014; Singh et al. 2016) and probabilistic methods based on historical rainfall records. The statistical methods or probabilistic methods used to evaluate landslide susceptibility or hazards are associated with the factors that affect landslide occurrences and determine hazard zones. In order to create a landslide hazard zone map, many statistical methods have been applied, such as fuzzy set methods (Gorsevski et al. 2003; Ercanoglu and Gokceoglu 2004; Tangestani 2004; Muthu et al. 2008; Singh et al. 2012, 2013), artificial neural network (ANN) methods (Gomez and Kavzoglu 2005; Yesilnacar and Topal 2005; Pradhan and
Lee 2010; Sarkar et al. 2010), logistic regression models (Bai et al. 2010; Akgun 2012; Sarkar et al. 2012; Paulín et al. 2014), etc. However, statistical models are largely dependent on the quality of data, as well as on the equations used. As an alternative, many researchers have focused on the mechanisms of landslides to assist in forecasting them based on quantitative assessments. Several physical models have been proposed, including steady hydrology (SHALSTAB and SINMAP) (Montgomery and Dietrich 1994; Pack et al. 1999), quasi-steady hydrology (dSLAM, IDSSM) (Wu and Sidle 1995; Dhakal and Sidle 2003) and transient hydrology (TRIGRS) (Baum et al. 2008; Baum and Godt 2010), etc. However, all these models assessed landslides based on grids rather than on slope units. Landslides are more accurately mapped based on slope units, rather than on grids.

Although spatial landslide hazard mapping is very important for risk assessment of landslides in the Loess Plateau, there has been little research on landslide initiation mechanisms in this area. In this study, we assumed that shallow landslides in the study area occur as a result of heavy rainfall. By combining an infinite-slope stability model with the assumption that loess strength decreases with increasing water content, concurrently with the inclusion of rainfall, we derived a physical model to assess the hazard of shallow landslides based on slope units. The model was used to assess the hazard of shallow landslides at the precipitation with return periods of $10,20,50$ and 100 years. Finally, these assessments based on slope units were compared with those from grids in the study area.

\section{Physical setting}

The city of Yan'an is located in the central part of the Yan River Basin; this river is the first tributary of the Yellow River. Yan'an is located near the geographical center of the Loess Plateau $\left(36^{\circ} 35^{\prime} 21^{\prime \prime} \mathrm{N}\right.$, $109^{\circ} 297^{\prime \prime} \mathrm{E}$, figure 1) and is one of the major cities in the Loess Plateau with its high population density, but with limited land area; consequently, it faces significant threats from landslides.

The topography of the Loess Plateau is characterised by alternating hills and gullies, of elevations between 800 and $1400 \mathrm{~m}$. The slope angle is steep in lower slope section and gentle in upper slope section, with an average of $23.5^{\circ}$. The stratigraphic unit in the area comprises primarily Quaternary strata (Zhang and Liu 2010). Quaternary loess spans the entire area of the Malan deposits (deposited in Late Pleistocene, upper 0-2 m thick, which have mostly disappeared due to erosion), Lishi deposits (deposited in Middle 

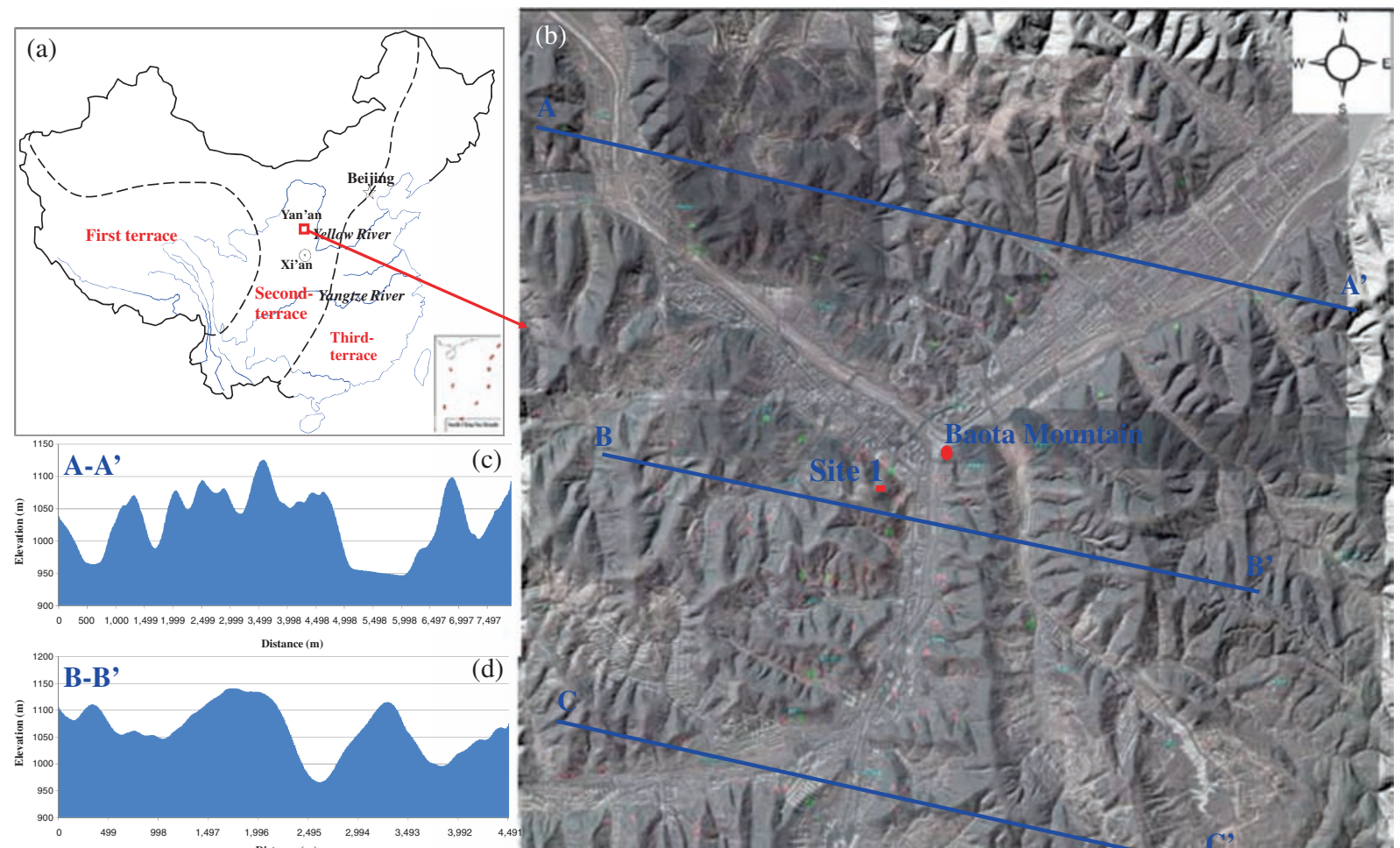

d)

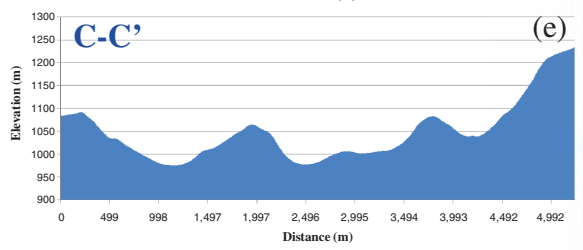

(e)

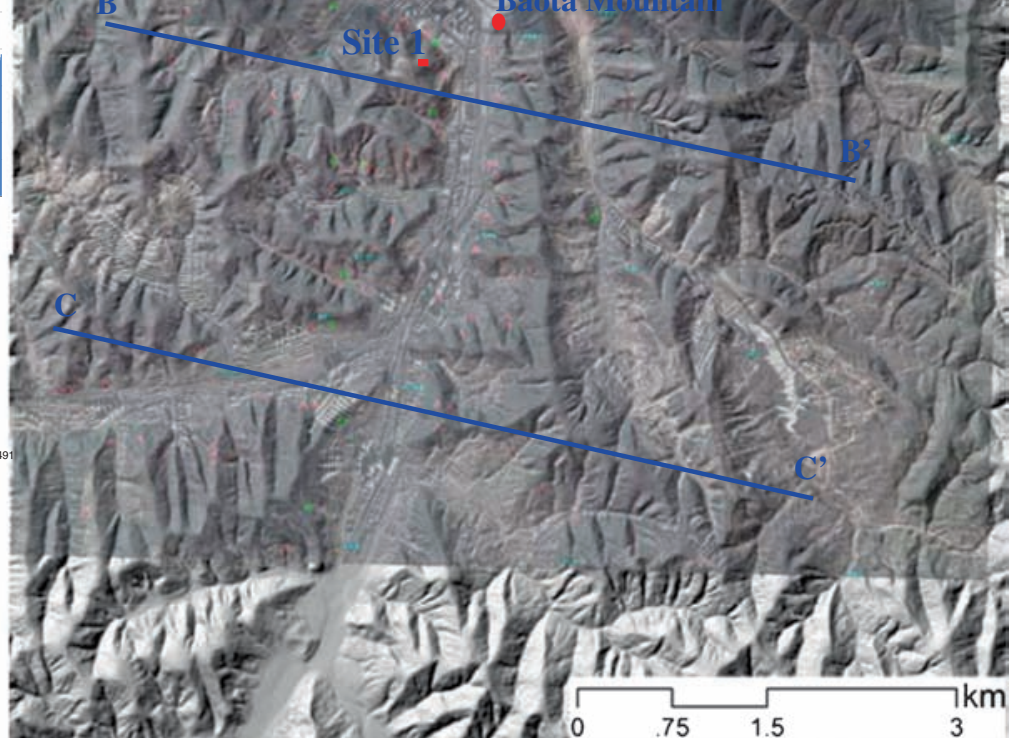

Figure 1. The physical setting of the study area. (a) Location in China; (b) the physical setting; (c) cross section of A-A'; (d) cross section of B-B'; and (e) cross section of C-C'.

Pleistocene, 40-60 m thick, which cover nearly the entire area of the plateau), and a few Wucheng loess deposits (deposited in Earlier Pleistocene) that are located in the lower of the Lishi Loess (Liu 1985).

The study area experiences a warm monsoon climate with four distinct seasons. The annual precipitation is between 520 and $550 \mathrm{~mm}$; however, most of the precipitation occurs in the form of rainstorms between June and September.

Because of the aforementioned factors, such as loose loess texture, joint structures and intensive human activity, the physical setting of the Yan'an region encourages the occurrence of landslides (Zhang and Liu 2010; Li et al. 2013a, b; Wang et al. 2015).

\section{Methodology}

\subsection{Slope units}

As indicated previously, most models have assessed the hazards of landslides based on grids, which is not in accordance with the actual landslide occurrences. In particular, the results of such approaches are dependent on DEM resolution (Claessens et al. 2005). Ideally, shallow landslide assessments should be based on slope units, the results of which can be used for risk assessment and mitigation. In this study, a new method is proposed to delimit slope units and determine the steepest slope profiles based on high resolution DEM and GIS (Geography Information System). The method of delimiting slope units is based on a GIS-based hydrological analysis and modelling tool, ArcHydro, which incorporates DEM and reverse DEM methods (Maidment 2002; Xie et al. 2003a, b; Wang et al. 2016, figure 2).

The infinite slope model has been widely used in shallow slope stability assessments (Montgomery and Dietrich 1994; Van Westen and Trelirn 1996; De Vleeschauwer and De Smedt 2002; Muntohar and Liao 2010). The slope angle is an important factor in this model. The average or longest slope profile has been used as a substitute for the slope gradient in many studies which is not reasonable for landslide assessment due to slope failures typically occur along the steepest slope profiles. Therefore, we proposed a method to determine the steepest 
slope profile, in order to assess overall slope stability (figure 3). First, the highest and lowest points are extracted; a diagram is then constructed from this data and a line is drawn between the two points. Next, the length of the line is calculated, and the slope angle is then be determined using the equation:

$$
\left(E_{1}-E_{2}\right) / L=\tan \alpha,
$$

where $E_{1}$ is the elevation of the highest point, $E_{2}$ is the elevation of the lowest point, $L$ is the distance between the projection point of $E_{1}$ on the horizontal line passing through $E_{2}$ and the point $E_{2}$, and $\alpha$ is the steepest angle of the corresponding slope unit.

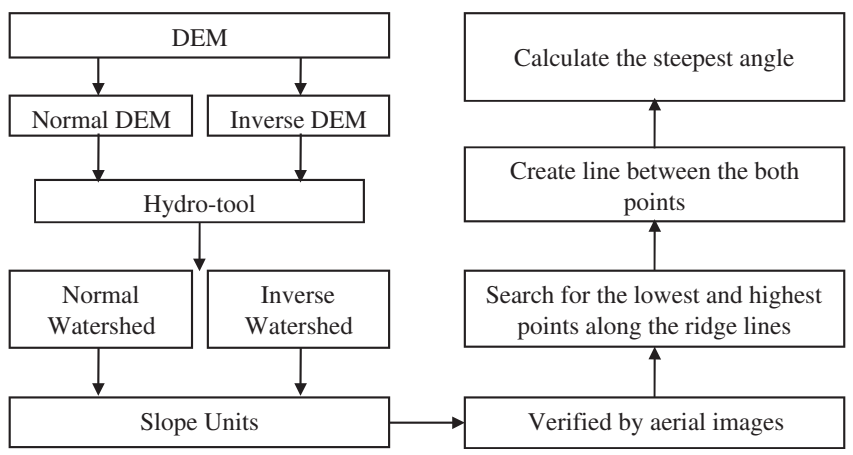

Figure 2. Chart of the process whereby a slope unit is delimited, after which the profile of the steepest slope can be drawn.
We proposed a tool to calculate the steepest slope profile, embedded into the ARCGIS Tools catalog using VB (Visual Basic). The slope unit and DEM are necessary parameters that should be determined before determining the slope profile (figure 3).

\subsection{Slope stability}

Since shallow landslides are common in the study area, where the slope length is greater than the soil depth, the infinite slope stability equation is applicable in this area. The proposed model compares the destabilizing and restorative components on a plane parallel to the soil surface, ignoring the boundary effect (Montgomery and Dietrich 1994;

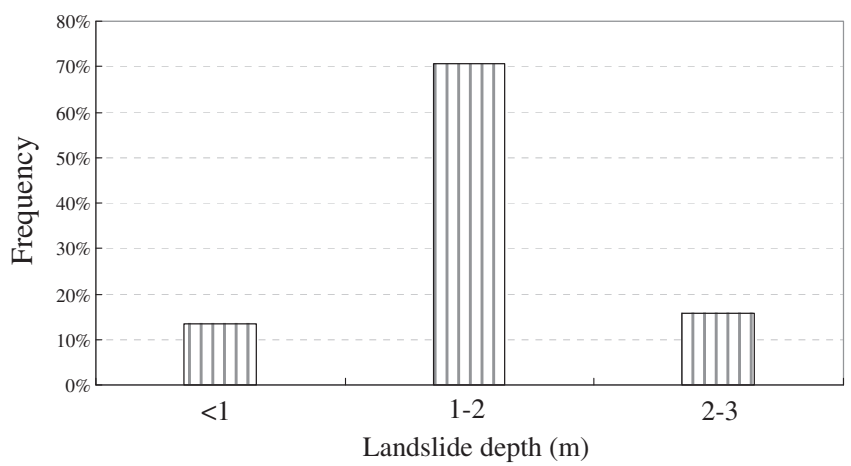

Figure 4. Distribution of landslide depths in the study area in response to prolonged, heavy rainfall in July 2013.

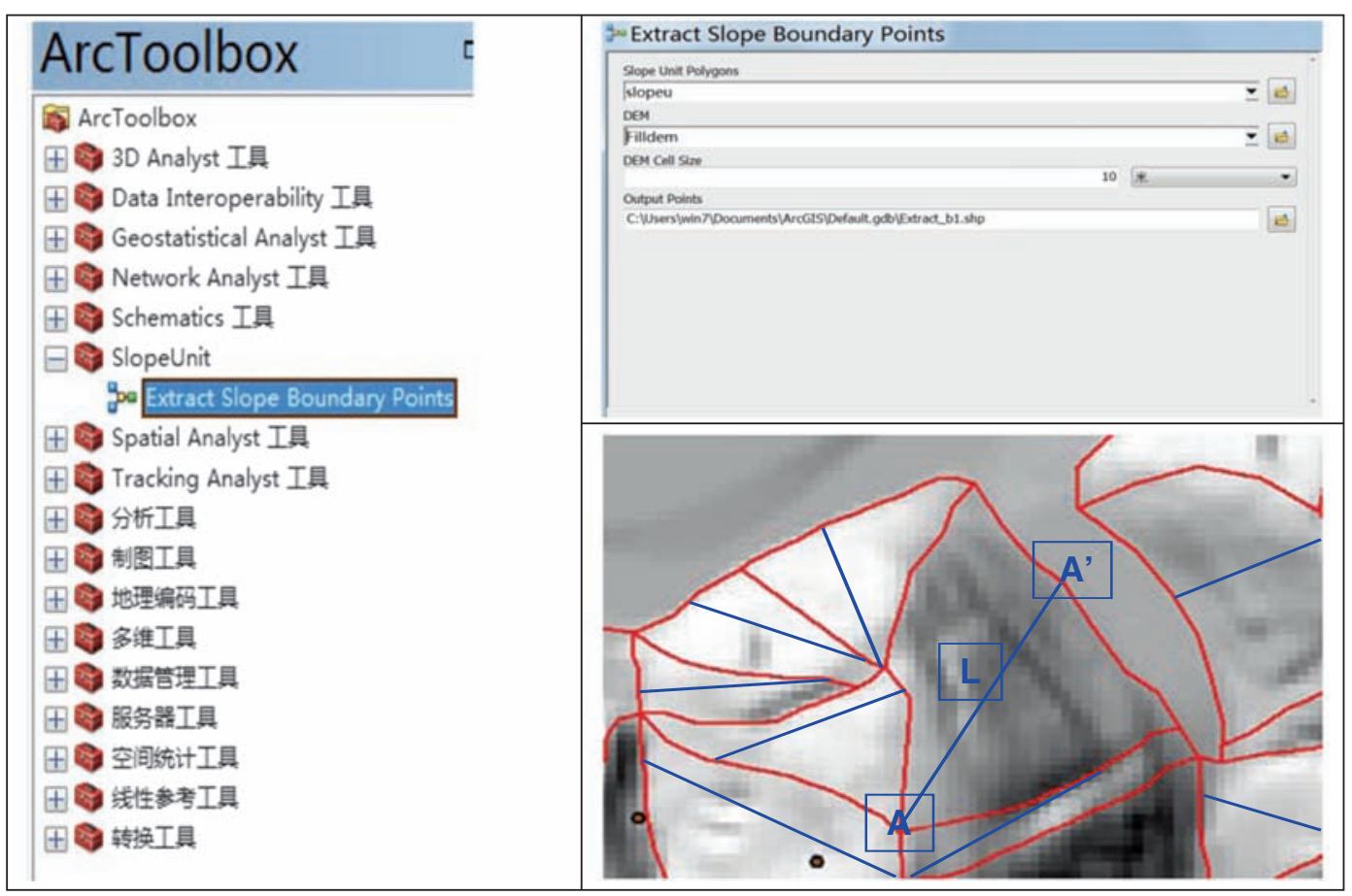

Figure 3. The ARCtool of steepest extract and results (A is the steepest point, $\mathrm{A}^{\prime}$ is the lowest point of the slope unit; $\mathrm{L}$ is the length from $\mathrm{A}$ to $\left.\mathrm{A}^{\prime}\right)$. 
Van Westen and Trelirn 1996; De Vleeschauwer and De Smedt 2002). The infinite slope stability equation is based on the Mohr-Coulomb law. At the moment when failure occurs, the shear stress, $\tau$ $\left(\mathrm{N} \cdot \mathrm{m}^{-2}\right)$, due to the down slope component of the weight of soil that fails, is equal to the resistance caused by cohesion, $c\left(\mathrm{~N} \cdot \mathrm{m}^{-2}\right)$ and by frictional resistance due to the effective normal stress on the failure plane (De Vleeschauwer and De Smedt 2002; Acharya et al. 2005), and is given by

$$
\tau=c+(\sigma-\mu) \tan \varphi
$$

where $\sigma$ is the normal stress $\left(\mathrm{N} \cdot \mathrm{m}^{-2}\right), \mu$ is the pore pressure opposing the normal load $\left(\mathrm{N} \cdot \mathrm{m}^{-2}\right)$, and $\varphi$ is the angle of internal friction of the soil (degrees). According to our investigation, the groundwater is
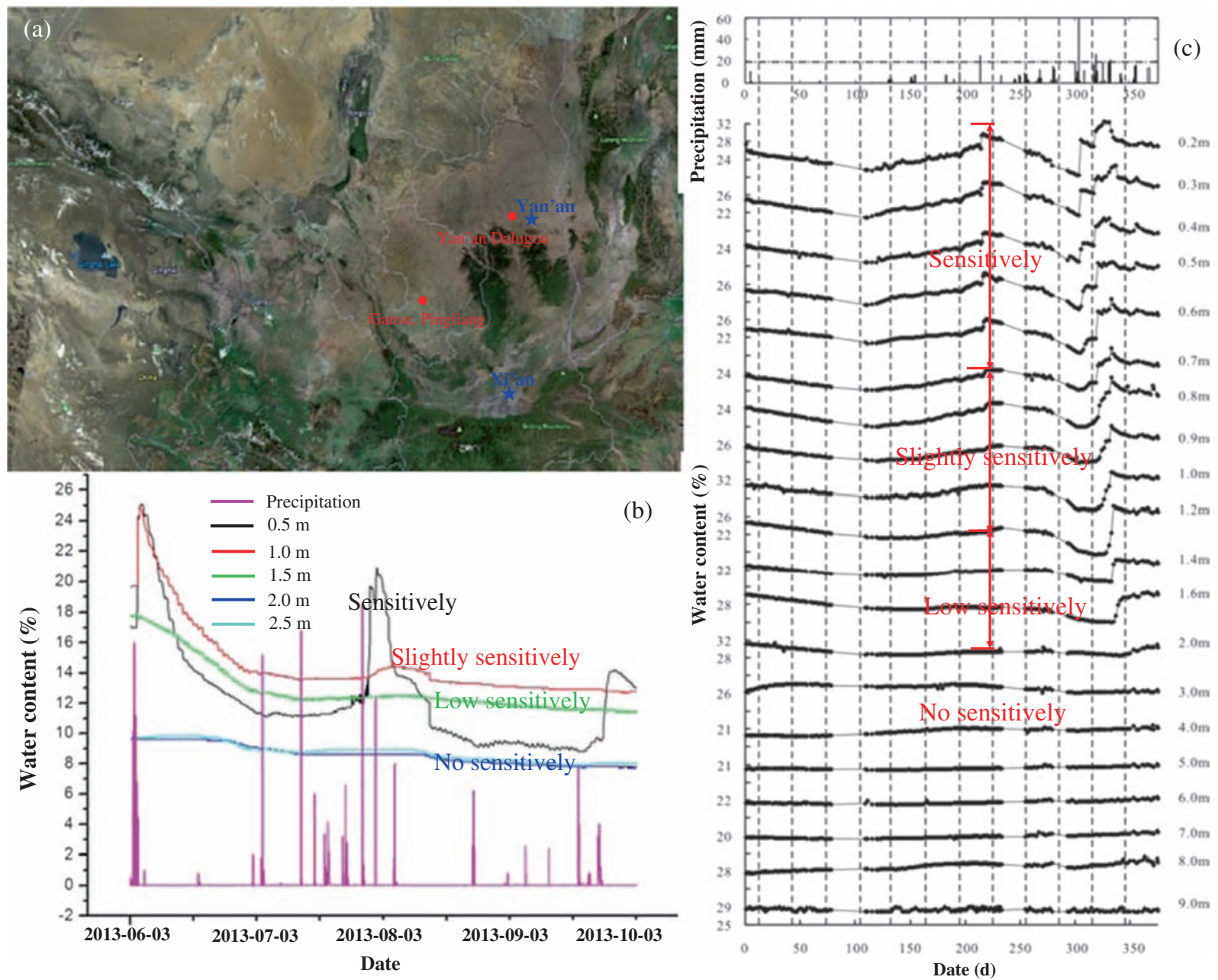

Figure 5. (a) Response of soil water content to precipitation in the Loess Plateau; (b) Yan'an Dalugou station; (c) Gansu Pingliang station. Data were obtained from Zhang et al. (2014).
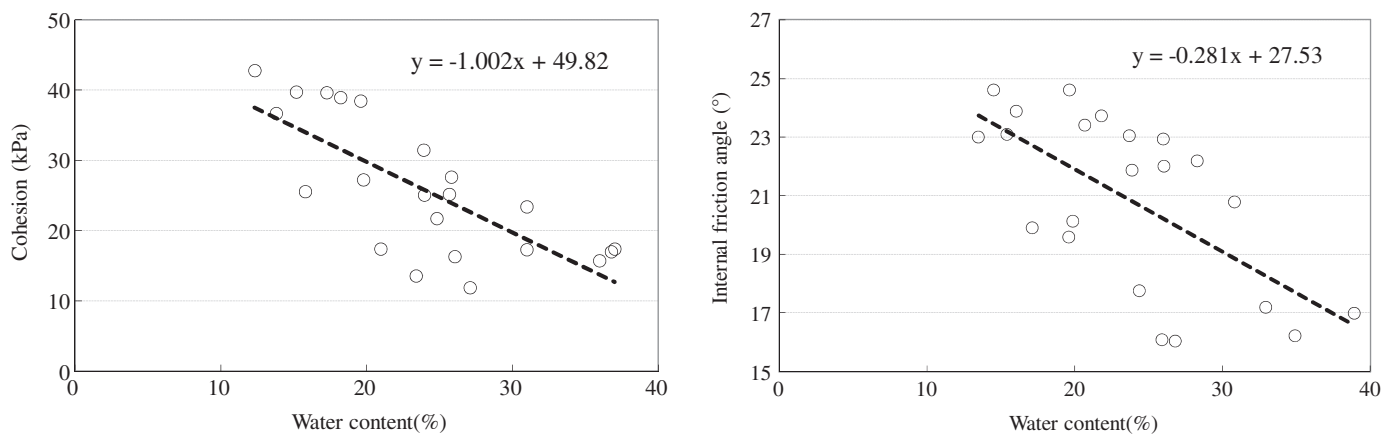

Figure 6. Cohesion and angle of internal friction in soil samples with different water contents. 
more than $30 \mathrm{~m}$ in the Loess Plateau, so $\mu$ can be neglected in this study. The shallow landslide stability equation can therefore be revised as:

$$
\tau=c+\sigma \tan \varphi
$$

In this equation, the variables $c$ (cohesion) and $\varphi$ (internal friction angle) of the sliding surface change as the water content increases, thus reducing slope stability. The depth of shallow landslides in the Loess Plateau is important for assessing slope stability and for calculating the $c$ and $\varphi$ of the sliding surface in relation to precipitation.
In order to determine the slope failure depth, we analysed all shallow landslides triggered by prolonged, heavy rainfall in the study area in July 2013 (figure 4). No landslide had a depth greater than $3 \mathrm{~m}$, and over $70 \%$ of the shallow landslides were no more than $2 \mathrm{~m}$ in depth. Meanwhile, two monitoring sites were established in the Loess Plateau (figure 5); five water content monitoring sensors were established at depths of 0.5, 1.0, 1.5, 2.0 and $2.5 \mathrm{~m}$, at the Yan'an Dalugou landslide monitoring site. Figure 5 indicates that the response of water content to precipitation decreased with increasing

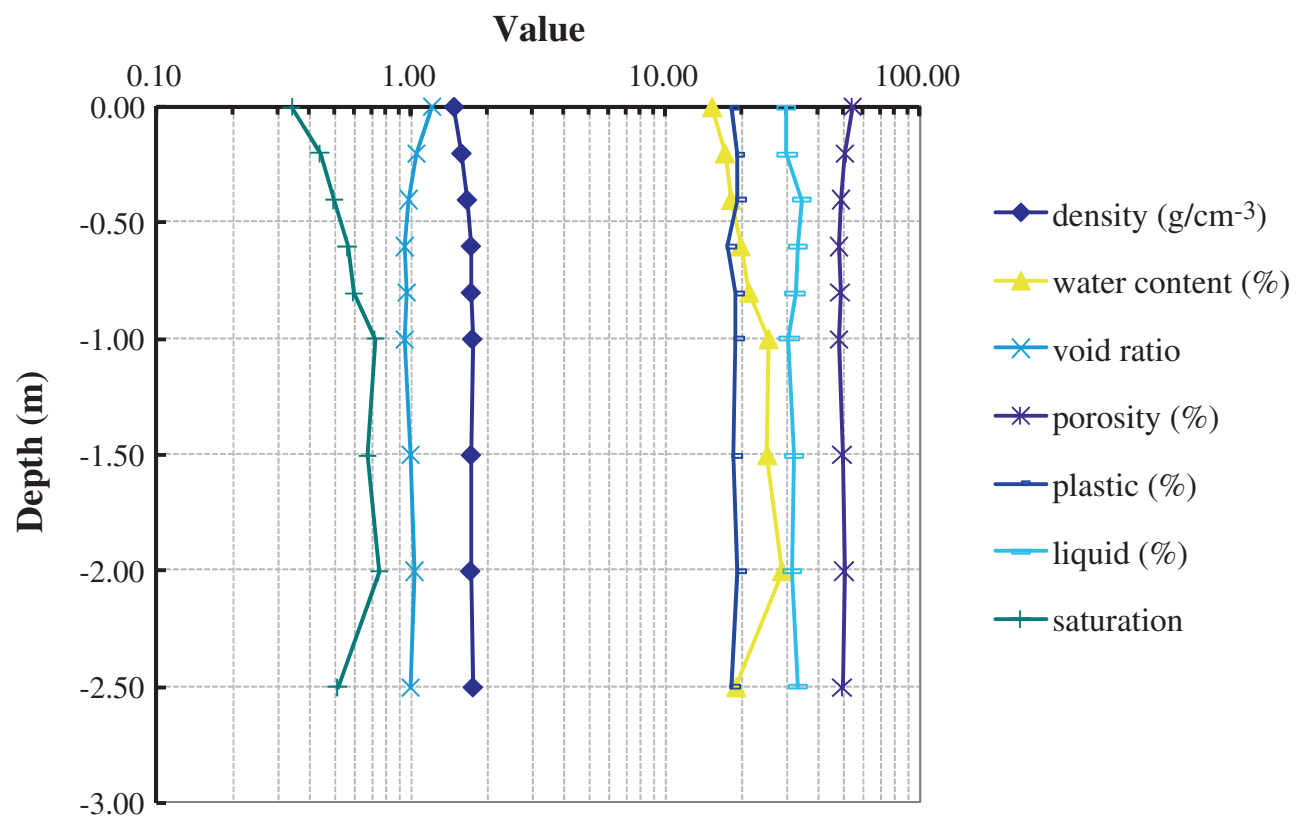

Figure 7. The soil physical parameters with depth at sample site 1.

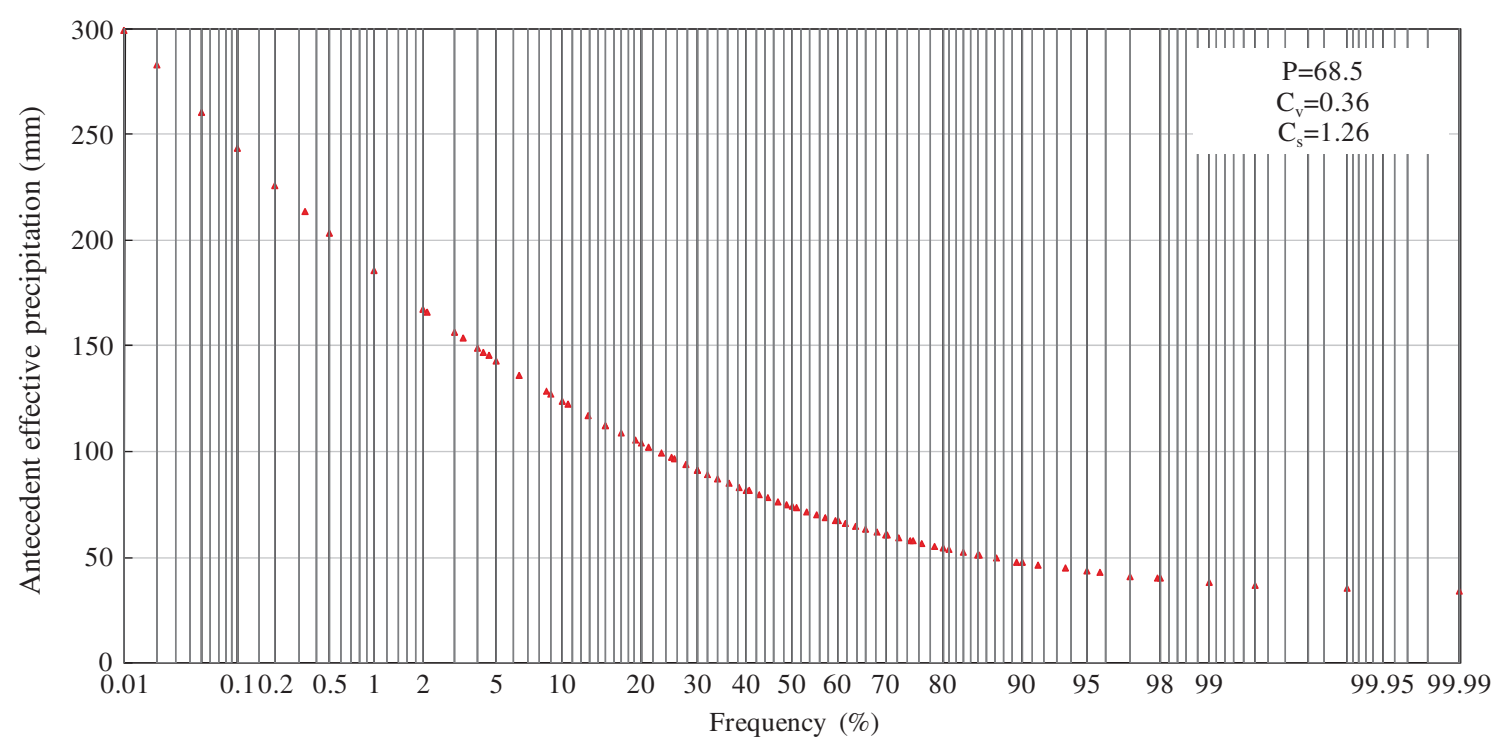

Figure 8. Antecedent effective precipitation over different return periods ( $\mathrm{P}$ is experience frequency; $\mathrm{Cv}$ is variation coefficient; Cs is skewness coefficient). 


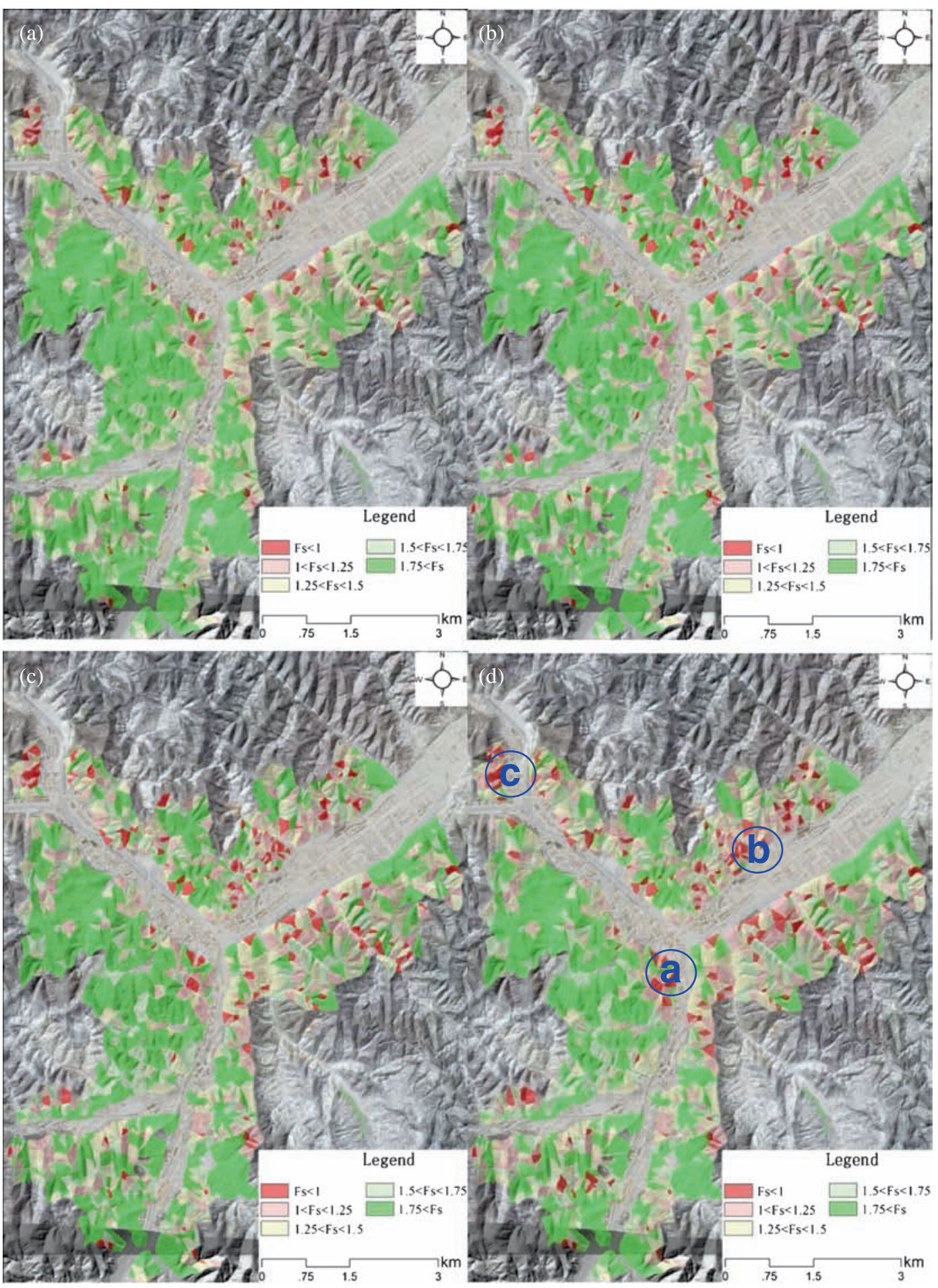

Figure 9. Slope unit stability at antecedent effective precipitation return periods of 10, 20, 50 and 100 years.

Table 1. The stability coefficient at different precipitation return periods (years).

\begin{tabular}{lcccc}
\hline Fs & $\begin{array}{c}\text { 100-year } \\
\text { return period }\end{array}$ & $\begin{array}{c}50 \text {-year } \\
\text { return period }\end{array}$ & $\begin{array}{c}20 \text {-year } \\
\text { return period }\end{array}$ & $\begin{array}{c}10 \text {-year } \\
\text { return period }\end{array}$ \\
\hline$<1$ & $6.2 \%$ & $4.6 \%$ & $3.4 \%$ & $2.8 \%$ \\
$1-1.25$ & $16.5 \%$ & $14.6 \%$ & $1.2 \%$ & $10.0 \%$ \\
$1.25-1.5$ & $21.5 \%$ & $21.2 \%$ & $19.6 \%$ & $18.1 \%$ \\
$1.5-1.75$ & $18.3 \%$ & $17.2 \%$ & $18.0 \%$ & $17.4 \%$ \\
$>1.75$ & $37.4 \%$ & $42.4 \%$ & $46.9 \%$ & $51.6 \%$ \\
\hline
\end{tabular}


depth. No response to precipitation was observed at a depth of $2.5 \mathrm{~m}$.

It was concluded that the maximum depth of infiltration (i.e., the maximum depth of the soil response to precipitation, namely, the sliding depth) was about $2.0 \mathrm{~m}$. This value was selected as the depth of the sliding surface of a shallow landslide in this study.

Song (1990) proposed the following equation to calculate soil saturation in relation to precipitation at a certain depth:

$$
S_{\mathrm{t}}=S_{0}+\frac{10 R_{\mathrm{e}}}{n Z}
$$

where $S_{0}$ is the initial soil saturation, $n$ is the porosity, $R_{\mathrm{e}}$ is the effective precipitation, and $Z$ is the depth of the infiltration of precipitation (the slope failure depth in this study).

Also,

$$
S_{\mathrm{t}}=\frac{w G_{\mathrm{s}}}{e}
$$

where $w$ is the water content, $G_{\mathrm{s}}$ is the bulk density, and $e$ is the void ratio. Thus, equation (4) can be written as:

$$
w_{\mathrm{t}}=w_{0}+\frac{10 R_{\mathrm{e}} e}{G_{\mathrm{s}} n Z},
$$

where $w_{0}$ and $w_{\mathrm{t}}$ are the initial and final water content, respectively. Next, loess soil was sampled at several locations in the study area, to assess the relationship between $c$ and $\varphi$ with increasing water content (figure 6). Analysis indicated that both parameters decreased with increasing water content $\left(w_{0}\right)$, indicated by the following equations:

$$
c=-1.002 w+49.82,
$$

$$
\varphi=-0.281 w+27.53
$$

Combining the above equations, the stability of a shallow landslide can be expressed as:

$$
\begin{aligned}
F_{s}= & \left\{\left(-1.002 w_{0}+49.82\right)+G_{\mathrm{s}} \mathrm{Z} \cos 2 \beta\right. \\
& \left.\times \tan \left(-0.281 w_{0}+27.53\right)\right\} \\
& /\left(G_{\mathrm{s}} Z \sin \beta \cos \beta\right) .
\end{aligned}
$$

In other words, stability of the slope can be determined using the effective precipitation, $R_{\mathrm{e}}$, initial water content $w_{0}, n, G_{\mathrm{s}}, Z, e$, and slope angle, $\beta$.

\subsection{Parameters assessed for determining slope stability}

The bulk density, void ratio, porosity and initial water content of soil were measured in samples obtained from different depths, ranging from 0 to $2 \mathrm{~m}$, in the study area. The sampling sites and the values of these parameters are indicated in figure 7 .

At sample site 1 (figure 1), the bulk density of the soil ranged from 1.48 to $1.75 \mathrm{~g} / \mathrm{cm}^{3}$ with a mean of $1.67 \mathrm{~g} / \mathrm{cm}^{3}$, while porosity ranged from $48.7 \%$ to $54.9 \%$ with a mean of $50.4 \%$. The initial water content of the soil ranged from $15.3 \%$ to $28.9 \%$ with a mean of $21.5 \%$.

Antecedent effective precipitation for different return periods was calculated based on historical records of antecedent effective precipitation using the Estimation Method (Thomas and Benson 1970). Figure 8 indicates the extrapolated values for antecedent effective precipitation over different return periods based on the maximum intraday rainfall recorded annually from 1959 to 2014 .

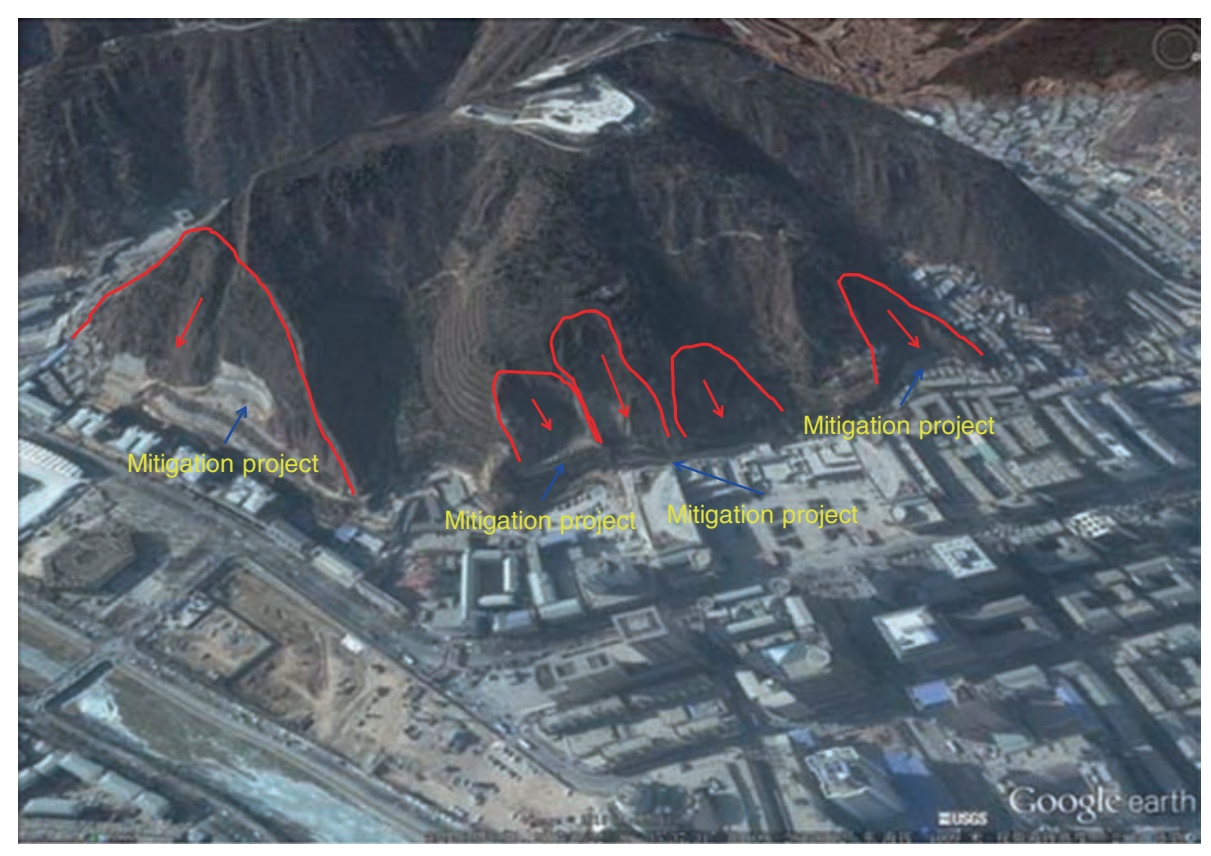

Figure 10. The existing slope failure and mitigation project in region 'a' of figure 9. 
Antecedent effective precipitation for 10-, 20-, 50and 100-year return periods were 123.9, 143.1, 167.5 and $185.5 \mathrm{~mm}$, respectively.

\section{Results and analysis}

A total of 2146 slope units were drawn around the city of Yan'an. The slope unit angles ranged from $5.4^{\circ}$ to $71.8^{\circ}$, with a mean of $28.5^{\circ}$, while the areas of slope units ranged from $15.3 \mathrm{~m}^{2}$ to $0.82 \mathrm{~km}^{2}$ with a mean of $0.07 \mathrm{~km}^{2}$. Slope unit stability was calculated using equation (9); the results for different return periods are indicated in figure 9.

The stability coefficient of equation (9) was divided into five categories related to degree of risk, based on the value of $F_{\mathrm{s}}$ : certain failure $(<1)$, possibility of failure (1-1.25), moderately stable $(1.25-1.5)$, stable $(1.5-1.75)$, and very stable $(>1.75)$ (table 1, figure 9). The number of slope units experiencing failure increased with effective antecedent precipitation, from $2.8 \%$ at 10 -year return period to $3.4 \%$ at 20 -year return period, $4.6 \%$ at 50 -year return period, and $6.2 \%$ at 100 -year return period (table 1, figure 9). The failed slope units displaying the greatest threats to human life are located in the three regions marked in figure 9 . In one of these regions ('a'), a landslide mitigation project is in progress (figure 10), with satisfactory results to date.

Figure 11 indicates all slopes with failures over the last few decades. The model suggested that most failures $(68.1 \%)$ were located in the first

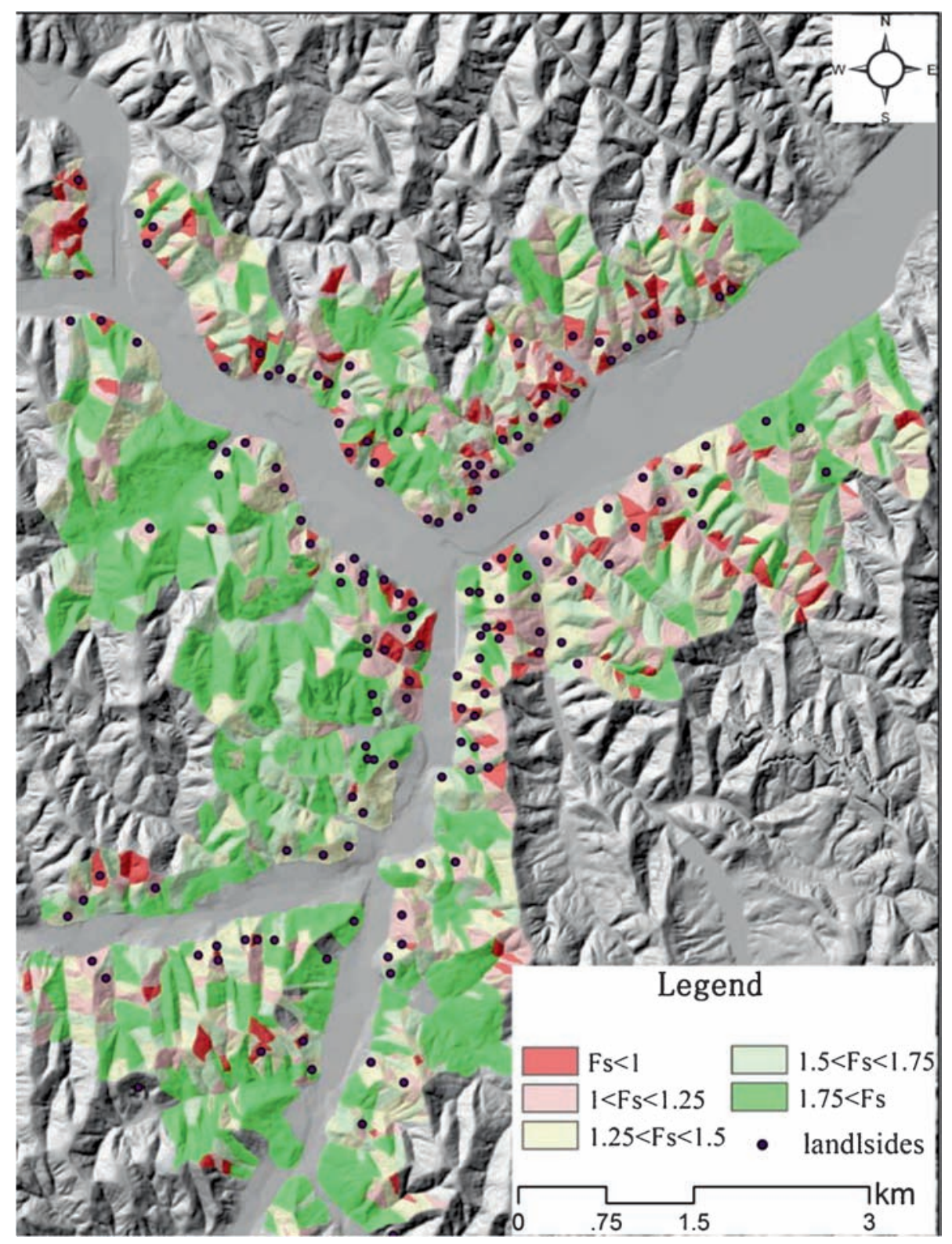

Figure 11. Comparison of slope failures in the last few decades with model predictions for an antecedent effective precipitation period of 100 years. 
two categories of slope units (certain failure and possibility of failure slope units over an antecedent effective precipitation period of 100 years). On the contrary, many landslides occurred in slope units are classified as stable or very stable. This discrepancy is due to the very common practice of slope cutting in this area.

\section{Limitations}

Although the results of this study mapped the risk of shallow landslides in the study area with reasonable accuracy, further optimization of the method with additional test data and high-resolution DEM is necessary.

A definition of the relationship between water content at a certain depth and antecedent effective precipitation was proposed by Song (1990). This equation has been applied to the Loess Plateau by other researchers, with the finding that it is accurate in estimating the soil water content at a certain depth based on antecedent effective precipitation in the Loess Plateau (Wang et al. 2004; Huang and He 2007; Zhuang et al. 2013). However, there is a spatial variation in infiltration because of differences in land use and slope gradients. It is necessary to map infiltration rates across the plateau and thus refine the equation further.

The precision of mapping slope units is based on DEM resolution. The area of the slope units mapped in our study is slightly larger than the actual landslide area, which resulted in some inaccuracy in forecasting in some areas.

\section{Conclusions}

1. A method using ARCtools to draw slope units and steepest slope profiles is proposed, based on DEM and reverse DEM technology.

2. Combining analysis of the water content and strength of the sliding surface, in response to precipitation with the infinite slope stability equation, an improved equation to calculate infinite slope stability is proposed to calculate the hazard of shallow landslide.

3. The methods were implemented in a case study in the city of Yan'an, north-west China. Slope unit stability was calculated at antecedent effective precipitation return periods of $10,20,50$ and 100 years.

4. The results were validated by actual landslide data during a comparable period. The method can be used successfully to assess the hazard of shallow landslides in the Loess Plateau. The accuracy of this method may be improved significantly by using high-resolution data.

\section{Acknowledgements}

The authors wish to thank Dr Fanyu Zhang, Yazhe $\mathrm{Li}$, Penghui Ma, Liyong Zhang and Dr Di Wu for their contributions and involvement in the field investigations and experiments. We would also like to express our gratitude to the academic and technical staff of the Institute of Geo-hazards Mitigation and Research of Chang'an University and Chen Wenbo from the CEE of the PolyU of HongKong, China. This study was financially supported by the National Basic Research Program of China (No. 2014CB744703), the National Natural Science Foundation of China (Grant Nos. 41572272, 41661134015 and 41130753) and the Central University Founding of the Chang'an University (310826163503). The authors would also like to acknowledge the two anonymous reviewers and the editor for their helpful comments on the earlier version of the manuscript.

\section{References}

Acharya G, De Smedt F and Long N T 2005 Assessing landslide hazard in GIS: A case study from Rasuwa, Nepal; Bull. Eng. Geol. Env. 65 99-107.

Akgun A 2012 A comparison of landslide susceptibility maps produced by logistic regression, multi-criteria decision, and likelihood ratio methods: A case study at İzmir, Turkey; Landslides 9(1) 93-106.

Baeza C and Corominas J 2001 Assessment of shallow landslide susceptibility by means of multivariate statistical techniques; Earth Surf. Proc. Land. 26(12) 1251-1263.

Bai S B, Wang J, Lü G N, Zhou P G, Hou S S and Xu S N 2010 GIS-based logistic regression for landslide susceptibility mapping of the Zhongxian segment in the Three Gorges area, China; Geomorphology 115(1) 23-31.

Baum R L and Godt J E 2010 Early warning of rainfallinduced shallow landslides and debris flows in the USA; Landslides 7 259-272.

Baum R L, Savage W Z and Godt J W 2008 TRIGRS A FORTRAN program for transient rainfall infiltration and grid based regional slope stability analysis, version 2.0; U.S. Geological Survey Open-File Report 2008-1159, p. 75 .

Caine N 1980 The rainfall intensity-duration control of shallow landslides and debris flows; Geogr. Ann. A 62 $23-27$.

Claessens L, Heuvelink G B M, Schoorl J M and Veldkamp A 2005 DEM resolution effects on shallow landslide hazard and soil redistribution modelling; Earth Surf. Proc. Land. 30(4) 461-477.

De Vita P, Reichenbach P, Bathurst J C, Borga M, Crosta G, Crozier M and Wasowski J 1998 Rainfall-triggered landslides: A reference list; Environ. Geol. 35(2) 219-233.

De Vleeschauwer C and De Smedt F 2002 Modeling slope stability using GIS on a regional scale; Proceedings of the first Geological Belgica International Meeting, Leuven, 11-15 September 2002; Aardkundige Mededelingen $12253-256$.

Derbyshire E, Meng X M and Dijkstra T A 2000 Landslides in the Thick Loess Terrain of North-West China; John Wiley \& Sons Ltd., London. 
Dhakal A S and Sidle R C 2003 Long-term modelling of landslides for different forest management practices; Earth Surf. Proc. Land. 28(8) 853-868.

Dijkstra T A, Rogers C D F and van Asch T W J 1995 Cut slope and terrace edge failures in Malan Loess, Lanzhou, PR China; In: Proceedings of the XI ECSMFE Conference, Copenhagen, pp. 61-67.

Ercanoglu M and Gokceoglu C 2004 Use of fuzzy relations to produce landslide susceptibility map of a landslide prone area (West Black Sea Region, Turkey); Eng. Geol. 75(3) 229-250.

Godt J W, Baum R L and Chleborad A F 2006 Rainfall characteristics for shallow landsliding in Seattle, Washington, USA; Earth Surf. Proc. Land. 31 97-110.

Gomez H and Kavzoglu T 2005 Assessment of shallow landslide susceptibility using artificial neural networks in Jabonosa River Basin, Venezuela; Eng. Geol. 78(1) $11-27$.

Gorsevski P V, Gessler P E and Jankowski P 2003 Integrating a fuzzy $\mathrm{k}$-means classification and a Bayesian approach for spatial prediction of landslide hazard; J. Geogr. Syst. 5(3) 223-251.

Gupte S S, Singh R, Vishal V and Singh T N 2013 Detail investigation of stability of in-pit dump slope and its capacity optimization; Int. J. Earth Sci. Eng. 6(2) 146-159.

Guzzetti F, Peruccacci S, Rossi M and Stark C P 2007 Rainfall thresholds for the initiation of landslides in central and southern Europe; Meteorol. Atmos. Phys. 98 239-267.

Guzzetti F, Peruccacc S, Ross M and Stark C P 2008 The rainfall intensity-duration control of shallow landslides and debris flows: An update; Landslides 5 3-17.

Huang Z Q and He P 2007 Research of slope stability on effective rainfall; J. North China Institute of Water Conservancy and Hydroelectric Power 28(3) 53-56 (in Chinese).

Li T L, Long J H and Li X S 2007 Types of loess landslides and methods for their movement forecast; J. Eng. Geol. 15(1) 500-506 (in Chinese).

Li T L, Wang C Y and Li P 2013a Loess deposit and loess landslides on the Chinese Loess Plateau; In: Progress of Geo-Disaster Mitigation Technology in Asia (eds) Wang F and Li T L, Environ. Sci. Eng., pp. 235-261.

Li T L, Wang C Y and Li P 2013b The mechanisms for initiation and motion of Chinese loess landslides; In: Progress of Geo-Disaster Mitigation Technology in Asia (eds) Wang $\mathrm{F}$ and Li T L, Environ. Sci. Eng., pp. 105-122.

Liu T S 1985 Loess and the environment; Science Press, Beijing (in Chinese).

Maidment D R 2002 Arc Hydro: GIS for water resources; Vol. 1, ESRI Inc.

Montgomery D R and Dietrich W E 1994 A physically based model for the topographic control on shallow landsliding; Water Resour. Res. 30(4) 1153-1171.

Muntohar A S and Liao H J 2010 Rainfall infiltration: Infinite slope model for landslides triggering by rainstorm; Nat. Hazards 54(3) 967-984.

Muthu K, Petrou M, Tarantino C and Blonda P 2008 Landslide possibility mapping using fuzzy approaches; Geosci. Remote Sens. 46(4) 1253-1265.

Pack R T, Tarboton D G and Goodwin C N 1999 SINMAP 2.0 - A stability index approach to terrain stability hazard mapping, User's manual; Terratech Consulting Ltd., Salmon Arm, Canada.

Paulín G L, Bursik M, Hubp J L, Mejía L M P and Quesada F A 2014 A GIS method for landslide inventory and susceptibility mapping in the Río El Estado watershed, Pico de Orizaba volcano, México; Nat. Hazards 71(1) 229-241.
Peng J B, Fan Z J, Di W, Zhuang J Q, Dai F C, Chen W W and Zhao C 2015 Heavy rainfall triggered loess-mudstone landslide and subsequent debris flow in Tianshui, China; Eng. Geol. 186(24) 79.

Pradhan B and Lee S 2010 Landslide susceptibility assessment and factor effect analysis: Back propagation artificial neural networks and their comparison with frequency ratio and bivariate logistic regression modelling; Environmental Modelling Software 25(6) 747-759.

Sarkar K, Tiwary A and Singh T N 2010 Estimation of strength parameters of rock using artificial neural networks; B. Eng. Geol. Environ. 69 599-606.

Sarkar K, Vishal V and Singh T N 2012 An empirical correlation of index geomechanical parameters with the compressional wave velocity; Geotechn. Geol. Eng. 30 469-479.

Singh R, Vishal V and Singh T N 2012 Soft computing method for assessment of compressional wave velocity; Scientia Iranica-Trans. Civil Eng. 19(4) 1018-1024.

Singh R, Vishal V, Singh T N and Ranjith P G 2013 A comparative study of generalised regression neural network approach and adaptive neuro-fuzzy inference systems for prediction of unconfined compressive strength of rock; Neural Comput. Appl. 23 499-506.

Singh T N, Singh R, Singh B, Sharma L K, Singh R and Ansari M K 2016 Investigations and stability analyses of Malin village landslide of Pune district, Maharashtra, India; Nat. Hazards 81(3) 2019-2030.

Song W R 1990 Frondtion engineering; Traslated by Wan G C, Beijing, Transportation Press, pp. 184-186.

Tangestani M H 2004 Landslide susceptibility mapping using the fuzzy gamma approach in a GIS, Kakan catchment area, southwest Iran; Aust. J. Earth Sci. 51(3) 439-450.

Thomas D M and Benson M A 1970 Generalization of stream flow characteristics from drainage-basin characteristics; US Geological Survey, Water Supply Paper 1975.

Van Westen C J and Trelirn T J 1996 An approach deterministic landslide hazard analysis in GIS: A case study Manizales (Colombia); Earth Surf. Proc. Land. 21 853-868.

Wang R G, Yan S W, Deng W D and Lu H X 2004 Reliability analysis of highway subgrade stability based on mean rainfall amount; Rock and Soil Mechanics 25(11) 1733-1738 (in Chinese).

Wang G, Zhang D, Furuya G and Yang J 2014 Pore-pressure generation and fluidization in a loess landslide triggered by the 1920 Haiyuan earthquake, China: A case study; Eng. Geol. 174 36-45.

Wang G, Li T, Xing X and Zou Y 2015 Research on loess flow-slides induced by rainfall in July 2013 in Yan'an, NW China; Environ. Earth Sci. 73(12) 7933-7944.

Wang Q, Li W, Wu Y, Pei Y, Xing $M$ and Yang D 2016 A comparative study on the landslide susceptibility mapping using evidential belief function and weights of evidence models; J. Earth Syst. Sci. 125(3) 645-662.

Wu W and Sidle R C 1995 A distributed slope stability model for steep forested basins; Water Resour. Res. 31(8) 2097-2110.

Xie M, Esaki T and Zhou G 2003a GIS method for slopeunit-based 3D landslide hazard evaluation; Chinese J. Rock Mech. Eng. 22(6) 969-976.

Xie M, Esaki T, Zhou G and Mitani Y 2003b Geographic information systems-based three-dimensional critical slope stability analysis and landslide hazard assessment; J. Geotech. Geoenviron. 129(12) 1109-1118.

Xu Z J, Lin Z G and Zhang M S 2007 Loess in China and loess landslides; Chin. J. Rock Mech. Eng. 26(7) 12971312 (in Chinese).

Xu L, Dai F C, Kang G L, Tham L G and Tu X B 2009 Analysis of some special engineering-geological 
problems of loess landslide; Chinese J. Geotech. Eng. 31(2) 288-292 (in Chinese).

Yesilnacar E and Topal T 2005 Landslide susceptibility mapping: A comparison of logistic regression and neural networks methods in a medium scale study, Hendek region (Turkey); Eng. Geol. 79(3) 251-266.

Zhang M S and Liu J 2010 Controlling factors of loess landslides in western China; Environ Earth Sci. 59 1671-1680.

Zhang D X, Wang G H, Luo C, Chen J and Zhou Y 2009 A rapid loess flowslide triggered by irrigation in China; Landslides 6(1) 55-60.

Zhang C L, Li P, Li T L and Zhang M S 2014 In-situ observation on rainfall infiltration in loess; Shuili Xubao 45(6) 728-734 (in Chinese).
Zhu T X 2012 Gully and tunnel erosion in the hilly Loess Plateau region, China; Geomorphology 153 144-155.

Zhuang J Q and Peng J B 2014 A coupled slope cutting - a prolonged rainfall-induced loess landslide: A 17 October 2011 case study; B. Eng. Geol. Environ. 73(4) 997-1011.

Zhuang J Q, Peng J B and Zhang L Y 2013 Risk assessment and prediction of shallow landslide at different precipitation in loess plateau; J. of Jinlin University (Earth Sci. Edn.) 43(3) 867-876 (in Chinese).

Zhuang J Q, Iqbal J, Peng J B and Liu T M 2014 Probability prediction model for landslide occurrences in Xi'an, Shaanxi Province, China; J. Mt. Sci. 11(2) $345-359$.

MS received 25 January 2016; revised 13 June 2016; accepted 23 June 2016

Corresponding editor: N V ChALAPATHI RAO 